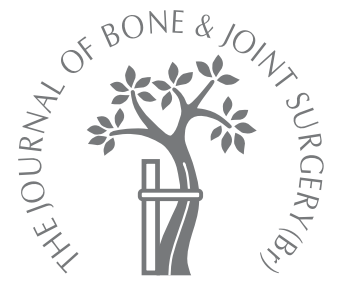

G. S. Gordon,

D. E. Simkiss

From the University

of Warwick,

Coventry, England

\title{
A systematic review of the evidence for hip surveillance in children with cerebral palsy
}

\author{
We reviewed the evidence for hip surveillance in children with cerebral palsy from the \\ published literature.
}

Publications were identified using the Cochrane controlled trials register, the MEDLINE, EMBASE and CINAHL databases and by hand searching key journals and their references. Studies were included if they reported the frequency, associated risk factors or surveillance measures undertaken to identify subluxation or dislocation of the hip in children with cerebral palsy. Assessment of the quality of the methodology was undertaken independently by two researchers.

Four studies described the natural history, incidence and risk factors for dislocation of the hip. Two reported their surveillance results. Approximately $60 \%$ of children who were not walking by five years of age were likely to develop subluxation of the hip, with the greatest risk in those with severe neurological involvement. The introduction of surveillance programmes allowed earlier identification of subluxation and reduced the need for surgery on dislocated hips.

Surveillance can identify children most at risk of subluxation using radiological methods which are widely available.

We undertook this systematic review of the literature in order to consider the evidence available to determine which children with cerebral palsy should undergo hip surveillance and what measures were effective in the identification of hip displacement.

\section{Materials and Methods}

Papers were included for scrutiny if they addressed the frequency of either dislocation or subluxation, risk factors or surveillance measures. The age limits were between 0 and 18 years, and children with congenital abnormalities of the spine or pelvis, or a history of previous orthopaedic surgery, were excluded. The following databases and strategies were used to identify papers:

1. Cochrane controlled trials register.

2. Cochrane systematic reviews.

3. Database of Abstracts of Reviews of Effects (DARE).

4. MEDLINE (OVID) incorporating EMBASE covering the years 1966 to April 2005.

5. Cumulative index to nursing and allied health literature (CINAHL) covering the years 1985 to April 2005.
6. Hand searching of key journals: Association of Paediatric Chartered Physiotherapists (APCP) Journal (September 1999 to September 2004), Archives of Diseases in Childhood (January 1995 to January 2005), Developmental Medicine and Child Neurology (January 1998 to January 2005).

7. Publications from known researchers in the field.

8. Hand searching of reference lists of papers found from the above sources.

The keywords and Medical subject headings (MeSH) terms were 'cerebral palsy' and 'hip', including 'dislocation' and 'subluxation'. The results were limited to 'human', 'all children aged 0 to 18 years' and the English language. Further key words such as 'measurement', 'surveillance', 'prevent", 'natural history', 'progression' and 'migration percentage' did not identify any new papers.

The MEDLINE and CINAHL search strategies are shown in Tables I and II.

MEDLINE identified 177 papers and CINAHL 31 different papers. Hand searching of the APCP journal identified five further studies. No other relevant papers were identified. Most of the papers found could be excluded by reference to their title or abstract, since they either 
Table I. Search strategy for MEDLINE (OVID plus), incorporating EMBASE. Parentheses denote the number of papers identified at each search stage

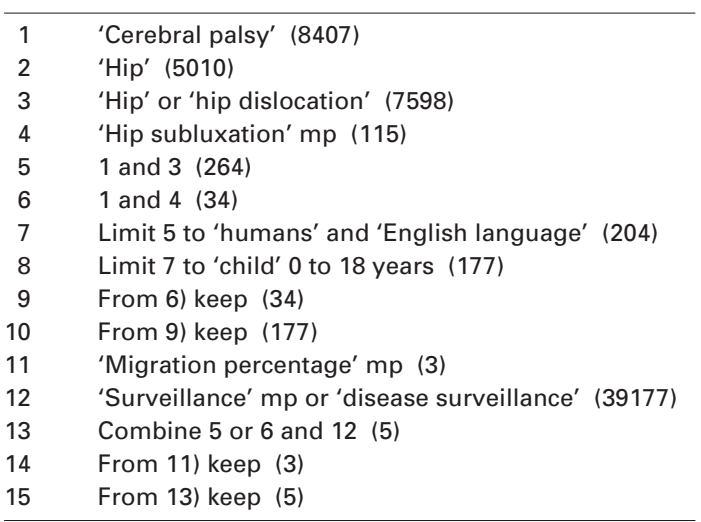

Table II. Search strategy for CINAHL database. Parentheses denote the number of papers identified at each search stage

\begin{tabular}{ll}
\hline 1 & 'Cerebral palsy' (1722) \\
2 & 'Hip' or 'dislocation' (1104) \\
3 & 'Subluxation' or 'hip subluxation' mp (654) \\
4 & Combine 1) and 2) (31) \\
5 & From 4) keep (31) \\
6 & Combine 1) and 3) (11) \\
7 & From 6) keep (11) \\
\hline
\end{tabular}

described surgical procedures or were reviews, editorials, letters or comments.

The full texts of 41 papers were obtained for further scrutiny and 28 of these were excluded. The remaining 13 were assessed according to specified criteria by the authors working independently. A quality-and-research relevance rating was assigned according to a checklist and scoring system (Table III) from a standard source. ${ }^{1}$ Seven studies fulfilled the inclusion criteria; ${ }^{2-8}$ two described the same series of children ${ }^{3,8}$ (Table IV).

Table $\mathrm{V}$ explains why the other seven studies were excluded. ${ }^{9-15}$

A descriptive summary of the results is presented. Formal meta-analysis is not recommended for systematic reviews of observational studies. ${ }^{16}$ In our study few papers gave sufficient detail to allow independent scrutiny of individual results.

\section{Results}

Table IV summarises the papers which were included. Children with quadriplegic cerebral palsy who cannot walk have the greatest risk of hip displacement. Cooke et $\mathrm{al}^{5}$ noted a prevalence of hip dislocation of $16 \%$ in a series from a tertiary centre. In a district population in the United Kingdom, $52 \%$ of children with quadriplegic cerebral palsy required treatment for a hip problem by the age of five years compared with $21 \%$ with diplegia. ${ }^{3}$
Table III. Details of the methodological quality-and-research rating system

\begin{tabular}{|c|c|c|c|c|}
\hline 1 & Study design appropriate to research question & $\mathrm{Y}$ & $\mathrm{N}$ & US \\
\hline 2 & $\begin{array}{l}\text { Sampling frame } \\
\text { Inclusion criteria } \\
\text { Diagnostic criteria defined } \\
\text { Sample selection explained } \\
\text { All eligible patients included } \\
\text { Representative }\end{array}$ & $\mathrm{Y}$ & $\mathrm{N}$ & US \\
\hline 3 & $\begin{array}{l}\text { Sample size adequate - either whole population of } \\
\text { interest or random sampling from a defined } \\
\text { population subset }\end{array}$ & $\mathrm{Y}$ & $\mathrm{N}$ & US \\
\hline 4 & Appropriate duration of follow-up & $\mathrm{Y}$ & $\mathrm{N}$ & US \\
\hline 5 & $\begin{array}{l}\text { Outcome } \\
\text { Objective } \\
\text { Assessors blinded to prognostic information } \\
\text { Fully defined }\end{array}$ & Y & $\mathrm{N}$ & US \\
\hline 6 & $\begin{array}{l}\text { Prognostic variable } \\
\text { Appropriately defined } \\
\text { Details of measurement method } \\
\text { Precisely measured } \\
\text { Data available in high proportion of patients }\end{array}$ & $\mathrm{Y}$ & $\mathrm{N}$ & US \\
\hline 7 & $\begin{array}{l}\text { Attrition } \\
\text { Drop-outs described } \\
\text { Outcome known for high proportion of patients }\end{array}$ & Y & $\mathrm{N}$ & US \\
\hline 8 & $\begin{array}{l}\text { Analysis } \\
\text { Continuous predictor variable analysed } \\
\text { appropriately } \\
\text { Statistical adjustment for prognostic factors }\end{array}$ & $\mathrm{Y}$ & $\mathrm{N}$ & US \\
\hline 9 & $\begin{array}{l}\text { Treatment } \\
\text { Subsequent to cohort inclusion } \\
\text { Fully described } \\
\text { Standardised or randomised }\end{array}$ & $\mathrm{Y}$ & $\mathrm{N}$ & US \\
\hline 10 & $\begin{array}{l}\text { For surveillance methods, additional consideration } \\
\text { must be given to the use of a control group } \\
\text { Random allocation } \\
\text { or description of any baseline differences }\end{array}$ & $Y$ & $\mathrm{~N}$ & US \\
\hline \multicolumn{5}{|c|}{$\begin{array}{l}\text { * ' } Y \text { ' (Yes); If there is insufficient information to make a judgement, op- } \\
\text { tions ' } N \text { ' (No) or 'US' (Unsure) must be used }\end{array}$} \\
\hline $\begin{array}{l}\text { A n } \\
\text { the } \\
1 \text { tc } \\
4 \text { tc } \\
7+\end{array}$ & $\begin{array}{l}\text { merical rating score is used to determine how useful } \\
\text { esearch questions under investigation, as follows: } \\
3 \text { Low relevance } \\
6 \text { Medium relevance } \\
\text { High relevance }\end{array}$ & a & per & for \\
\hline
\end{tabular}

Scrutton et $\mathrm{al}^{3}$ provided the most information regarding locomotor development and progressive hip problems. No child who had walked ten steps alone by 30 months needed treatment of their hips by five years of age. Children who at five years of age could walk ten steps unaided had a markedly reduced need for treatment $(4.1 \%$ vs $46 \%$ for those unable to walk). The severity of motor disability at 18 months of age was not predictive of hip displacement, but by 24 to 30 months of age, it was. A greater proportion of females required treatment $(38.8 \%$ vs $32.8 \%)$ and presented with bilateral hip problems $(23.9 \%$ vs $20.6 \%)$, but 
Table IV. Summary of the results

\begin{tabular}{|c|c|c|c|}
\hline \multirow{2}{*}{$\begin{array}{l}\text { Authors } \\
\text { Scrutton et } \mathrm{al}^{3}\end{array}$} & \multicolumn{2}{|c|}{$\begin{array}{l}\text { Methodological rating } \\
\text { by two reviewers }\end{array}$} & \multirow{2}{*}{$\begin{array}{l}\text { Annotated results } \\
\text { Of } 323 \text { children, } 117(36.2 \%) \text { had } 196 \text { hips ( } 30.3 \%) \text { needing treatment. } 52 \% \text { of children with quadriplegic } \\
\mathrm{CP}^{*} \text { and } 21 \% \text { of children with diplegic CP needed treatment by } 5 \text { years of age }(\mathrm{p}<0.01) \text {. No child who } \\
\text { walked by } 30 \text { months had a hip problem ( } \mathrm{n}=69) \text {. } 8 \text { of } 52 \text { children }(15.3 \%) \text { who walked between } 30 \text { months } \\
\text { and } 5 \text { years had a hip problem. } 109 \text { of } 202 \text { children }(53.9 \%) \text { not walking by five years had a hip problem. } \\
38.8 \% \text { female to } 32.8 \% \text { males had hips needing treatment. No effect of gestational age or birth-weight }\end{array}$} \\
\hline & High & High & \\
\hline Hagglund et $\mathrm{al}^{7}$ & High & High & $\begin{array}{l}\text { Surveillance group }(n=236) .50 \text { children had a total of } 78 \text { subluxed hips (migration percentage }>33 \% \text { ). } 54 \\
\text { of } 78 \text { required surgery. No dislocations. Control group }(n=103) .8 \text { children's hips dislocated, } 9 \text { children } \\
\text { with subluxed hips required surgery. All hips with an increased acetabular index }\left(>30^{\circ}\right) \text { also had a } \\
\text { migration percentage greater than } 33 \%\end{array}$ \\
\hline Dobson et $\mathrm{al}^{6}$ & Medium & Medium & $\begin{array}{l}\text { Mean age of referral to surveillance clinic (HSC) was } 3.75 \text { years ( } 1 \text { to } 15 \text { ), younger than that of } \\
\text { conventional surgical clinic (not recorded). Criteria for surgery based upon migration percentage, } \\
\text { progression rate and acetabular index value. Preventative surgery pre-HSC (1996 to } 1997) 51 \% \text {, after HSC } \\
\text { (1999 to } 2000 \text { ) } 70.9 \% \text {. Reconstructive surgery pre-HSC } 37 \% \text {, after HSC } 29 \% \text {. Salvage surgery pre-HSC } \\
11.4 \% \text {, after HSC no cases }\end{array}$ \\
\hline Miller and Bagg ${ }^{4}$ & Medium & High & $\begin{array}{l}38 \text { of } 61 \text { hips with low migration percentage (migration percentage }<30 \% \text { ) remain unchanged, } 28 \text { of } 33 \\
\text { hips with migration percentage between } 30 \% \text { and } 60 \% \text { remain unchanged. Both hips with migration } \\
\text { percentage }>60 \% \text { progressed to dislocation. Spontaneous improvement in migration percentage in } 6 \\
\text { patients but related to contralateral dislocation in } 3 \text { patients }\end{array}$ \\
\hline Cooke et $\mathrm{al}^{5}$ & Medium & High & $\begin{array}{l}\text { Risk of hip dislocation virtually confined to quadriplegic } \mathrm{CP}(\mathrm{n}=235) \text { where prevalence was } 16 \% \text {. Increas- } \\
\text { ing migration index, at varying rates for those who dislocated. Ranges of acetabular index showed more } \\
\text { discrete differences between dislocators and non-dislocators than migration index. Values were higher in } \\
\text { those who dislocated. Non-dislocators showed migration index }<45 \% \text { at any age and had normal } \\
\text { acetabular index. Predicted dislocation from single radiograph }>95 \% \text { of cases, false negative rate } 4.2 \%\end{array}$ \\
\hline Vidal et $\mathrm{al}^{2}$ & Low & Medium & $\begin{array}{l}\text { No information on raw data - extrapolated from graphs and text. Rate of linear progression of migration } \\
\text { percentage is } 7.7 \% \text { per year without surgery. Acetabular angle under } 5 \text { years - no prognostic significance. } \\
\text { Coxa valga exceeding } 160^{\circ} \text { is a bad prognostic sign, occurring in } 75.4 \% \text { of non-walking children with high } \\
\text { migration percentage }\end{array}$ \\
\hline
\end{tabular}

* CP, cerebral palsy

Table V. Reasons for exclusion of reviewed papers

\begin{tabular}{|c|c|}
\hline Authors & Reason for exclusion \\
\hline Samilson et $\mathrm{al}^{9}$ & Retrospective case review. Adult and child figures combined. Age range: 4 months to 50 years. No further data supplied \\
\hline Howard et al $^{10}$ & Retrospective records review. Adult and child figures combined. Age 6 months to 28 years \\
\hline Lonstein and Beck ${ }^{11}$ & $\begin{array}{l}\text { Retrospective records review. Adult and child figures combined. Age range } 1 \text { year to } 35 \text { years. Range of most severely } \\
\text { affected group with hip dislocation from } 2 \text { to } 19 \text { years }\end{array}$ \\
\hline Sauser, et al ${ }^{12}$ & Retrospective records review. Adult and child figures combined. Age range 1 to 60 years \\
\hline Black et $\mathrm{al}^{13}$ & $\begin{array}{l}\text { Case study of five patients with hip obliquity, investigating the mechanism of hip dislocation. Not directly relevant to the } \\
\text { research questions of the review }\end{array}$ \\
\hline Metaxiotis et $\mathrm{al}^{14}$ & $\begin{array}{l}\text { Descriptive study investigating gait patterns of ambulant children with cerebral palsy and unilateral hip dysplasia. Not } \\
\text { directly relevant to the research questions of the review }\end{array}$ \\
\hline Hodgkinson et al ${ }^{15}$ & Cross-sectional study investigating incidence of pain. Not directly relevant to the research questions of the review \\
\hline
\end{tabular}

this could be explained by a larger proportion of boys who could walk (34.3\% females, $48.7 \%$ males). Females had a significantly higher early migration percentage and acetabular index scores, perhaps because of oestrogen-influenced joint laxity or anatomical differences in the pelvis which affected the direction of forces of the local spastic muscles.

Radiological measurement of the migration percentage and acetabular index can monitor hips at risk of subluxation. In the series of Miller and Bagg, ${ }^{4} 16$ of 21 hips in children between the age of two and six years remained unchanged over a period of eight years, whereas hips with a migration percentage of between $30 \%$ and $60 \%$ had a risk of further subluxation of $25 \%$. Hips with a migration percentage of over $60 \%$ went on to dislocate. However, this study was restricted to patients who had been followed up for at least eight years. It did not consider all children with dislocated hips and thereby excluded those at highest risk.

Vidal et $\mathrm{al}^{2}$ noted an increase in the migration percentage from as early as 12 months of age. This did not reach the clinically significant $40 \%$ until a few years later in most 
children. The annual rate of progression of the migration percentage, without surgery was $7.7 \%$ in the child unable to walk.

Acetabular obliquity did not show any relationship to the migration percentage before 30 months and only became apparent when it exceeded $20 \%$. Scrutton et $\mathrm{al}^{3}$ showed a clear correlation between the migration percentage and the acetabular index, which became stronger as the child approached 48 months. The graphs of Cooke et $\mathrm{al}^{5}$ for the groups which dislocated showed an increasing migration index with time, although at differing rates.

Two papers found that surveillance programmes eliminated the need for salvage surgery on dislocated hips. ${ }^{6,7}$ Each used the migration percentage and acetabular index to identify hips with progressive subluxation. In the study of Dobson et al, ${ }^{6}$ the rate of preventative surgery was $70.9 \%$ after surveillance compared with $51 \%$ beforehand, whereas the rate of reconstructive and salvage surgery fell from $37.1 \%$ and $29 \%$ to $11.4 \%$ and $0 \%$, respectively. Surgery was undertaken at a significantly younger age (mean 4.2 years, 1.5 to 7.6 ) compared with that in the conventional clinic (mean 8.3 years, 1.4 to 19 ).

In the study of Hagglund et al, 54 of 78 hips $(50$ children) with a migration percentage greater than $33 \%$ required surgery, but in 18 hips it corrected to less than $33 \%$ without operation. No hip with a migration percentage greater than $42 \%$ became normal without operation. All hips with an acetabular angle above $30^{\circ}$ had a migration percentage greater than $33 \%$; 13 children had been treated by new techniques for reducing spasticity, nine undergoing dorsal rhizotomy and four, treatment with intrathecal baclofen. In these children, the migration percentage decreased in 11 and was unchanged in two.

\section{Discussion}

The six papers examined in detail were a mixture of retrospective and prospective studies; two ${ }^{6,7}$ compared results with historical controls. Scrutton et $\mathrm{al}^{3}$ related their data to those of a normal population. The epidemiology also varied. Four studies were carried out at tertiary centres, ${ }^{2,4-6}$ and two at centres across a region. ${ }^{3,7}$ Miller and $\mathrm{Bagg}^{4}$ specifically excluded dislocated hips. Their review spanned several decades during which period the treatment of comorbidities had changed, thereby potentially influencing pooled results. Although all the studies used similar radiological measurements, the results were reported differently and the thresholds for intervention varied.

Three observational studies ${ }^{3,6,7}$ conducted with efficient methodological rigour were identified. Previous figures for the prevalence of hip dislocation in cerebral palsy have varied between $2 \%$ in those who could walk ${ }^{17}$ to $28 \%$ in the most severely affected, ${ }^{9}$ but they included adults. Hagglund et $\mathrm{al}^{7}$ suggested that the natural risk for dislocation of the hip in a population of children with cerebral palsy was between $15 \%$ and $20 \%$, based on an assumption that the $16.1 \%$ of children in their series who required preventative surgery would have dislocated without treatment.

All six studies used radiological measurements to monitor hip displacement and two performed clinical assessments of locomotor ability. ${ }^{2,3}$ Different methods of measuring radiographs have been described ${ }^{18-22}$ but the technique most often used is the migration index of Reimers, ${ }^{18}$ expressed as a percentage.

Several papers describe reliability and repeatability in the measurement of migration percentage and acetabular index ${ }^{23-}$ 25 and values for normal children allow those at risk to be identified. ${ }^{26}$ Hagglund et $\mathrm{al}^{7}$ identified children who required surgery as those with a migration percentage greater than $33 \%$ and an acetabular angle above $30^{\circ}$. Further radiographs at intervals of six months were recommended before any surgical decision was made because a proportion of hips with a migration percentage above $33 \%$ can stabilise or return to normal. Studies of validity have shown that a change greater than $8.3 \%$ in migration percentage and more than $3.7^{\circ}$ in the acetabular index represent a real change in displacement of the femoral head with $95 \%$ confidence. ${ }^{23}$

Cooke et $\mathrm{al}^{5}$ reported that dislocation developed only in the presence of acetabular dysplasia. Since this always occurred well before dislocation, its presence may indicate that it is a more reliable measurement. However, Scrutton et $\mathrm{al}^{3}$ and Hagglund et $\mathrm{al}^{7}$ found that the migration percentage was a better early warning of problems with the hip than the acetabular index.

The reproducibility and reliability of the acetabular index have also been questioned because the index varies with the orientation of the pelvis. It decreases with extension (lordosis) and increases with flexion. It also varies with rotation. Although rotation can be seen radiologically, there is no satisfactory method of checking flexion or extension, other than clinical positioning. Overall, the measurement of the acetabular index is prone to significant error. ${ }^{21}$ Its reliability also decreases with the size of the femoral head and increasing age over eight years. ${ }^{23}$ Conversely, the reliability of the migration percentage improves with growth, allowing monitoring into adolescence. Further study is needed for children under the age of eight years. ${ }^{23}$

With regard to the rate of subluxation, there is little evidence as to how often radiographs should be taken. Tonnis ${ }^{26}$ found that the $90^{\text {th }}$ centile for the migration percentage was $10 \%$ in normally developing children, with spontaneous migration limited to less than $1 \%$ per year. Vidal et $\mathrm{al}^{2}$ reported an annual rate of increase in the migration percentage of $7.7 \%$ in those unlikely to walk, but only up to $4 \%$ per year in those with walking potential.

The conclusion of Miller and $\mathrm{Bagg}^{4}$ that annual radiographs would suffice on the basis that the rate of progression of migration percentage never exceeded $20 \%$ per year, is debatable. They excluded all children with dislocated hips, including those who had a dislocation during their study. Annual radiographs for all patients would miss those known to dislocate rapidly. $3,6,7$ 
Dobson et $\mathrm{al}^{6}$ and Hagglund et $\mathrm{al}^{7}$ demonstrated that a surveillance programme prevented later hip dislocation. The latter reported that surveillance should begin at 18 months or earlier, based on the work of Samilson et $\mathrm{al}^{9}$ which showed hip displacement before 18 months. However, the latter study included infants as young as four months in whom dislocation was more likely to be because of a congenital anomaly or developmental dysplasia. Therefore, the results may not accurately represent the risk for infants with cerebral palsy.

Scrutton et $\mathrm{al}^{3}$ and Scrutton and Baird ${ }^{8}$ were rigorous in their classification of motor disorder and radiological method. In order to reduce radiation exposure the first radiograph was delayed until the age of 30 months, corrected for gestational age unless there was clinical concern earlier.

Dobson et $\mathrm{al}^{6}$ and Hagglund et $\mathrm{al}^{7}$ found that monitoring of the migration percentage and acetabular index identified children for surgery at a younger age, thereby preventing the need for salvage operations. However, it is not clear whether those undergoing early preventative surgery would require later reconstruction.

As to which children with cerebral palsy should undergo hip surveillance, the studies highlight spastic quadriplegia. Children with hemiplegia, and those with bilateral cerebral palsy who can walk independently by 30 months, rarely have hip instability. Of children with quadriplegia, $52 \%$ ( $45 \%$ of hips) needed treatment by five years of age compared with $21 \%$ of children (16\% of hips) with diplegia. Those who could not walk by the age of five years were most affected $(54 \%)$.

As to which surveillance measures are effective, the migration percentage and acetabular index are useful, although standardised methods for positioning and measurement are required. ${ }^{27}$ Acetabular dysplasia is always present with dislocation. All hips with an acetabular index of more than $30^{\circ}$ at 30 months had a hip problem by five years of age. A migration percentage of $15 \%$ or more at 30 months carried a risk of dislocation of more than $50 \%$ and needs careful monitoring. Hips with a migration percentage over $60 \%$ are unstable and require immediate attention.

Our systematic review confirms the guidelines of Scrutton et al. ${ }^{3}$ All children with bilateral cerebral palsy should have a radiograph of the hip at the age of 30 months. Clinical suspicion beforehand merits a radiograph. Although the migration percentage and acetabular index are useful, the former is more valuable and continues to be reliable beyond eight years of age.

Children with a migration percentage greater than $33 \%$, or an acetabular index over $30^{\circ}$, are likely to need further treatment. A progression of the migration percentage by more than $7 \%$ per annum requires careful monitoring and consideration for orthopaedic referral.
No benefits in any form have been received or will be received from a commercial party related directly or indirectly to the subject of this article.

\section{References}

1. Egger M, Davey-Smith G, Altman DG. Systematic reviews in health care. London: BMJ Publishing Group, 2001

2. Vidal J, Deguillaume P. Vidal M. The anatomy of the dysplastic hip in cerebral palsy related to prognosis and treatment. Int Orthop 1985;9:105-10.

3. Scrutton D, Baird G, Smeeton N. Hip dysplasia in bilateral cerebral palsy: incidence and natural history in children aged 18 months to 5 years. Dev Med Child Neurol 2001;43:586-600.

4. Miller F, Bagg MR. Age and migration percentage as risk factors for progression in spastic hip disease. Dev Med Child Neurol 1995;37:449-55.

5. Cooke PH, Cole WG, Carey RP. Dislocation of the hip in cerebral palsy: natural history and predictability. J Bone Joint Surg [Br] 1989;71-B:441-6.

6. Dobson F, Boyd RN, Parrott J, Nattrass GR, Graham HK. Hip surveillance in children with cerebral palsy: impact on the surgical management of spastic hip disease. J Bone Joint Surg [Br] 2002;84-B:720-6.

7. Hagglund G, Andersson S, Duppe H, et al. Prevention of dislocation of the hip in children with cerebral palsy: the first ten years of a population-based prevention programme. J Bone Joint Surg [Br] 2005;87-B:95-101.

8. Scrutton D, Baird G. Surveillance measures of the hips of children with bilateral cerebral palsy. Arch Dis Child 1997;76:381-4

9. Samilson RL, Tsou P, Aamoth G, Green WM. Dislocation and subluxation of the hip in cerebral palsy: pathogenesis, natural history and management. J Bone Joint Surg [Am] 1972;54-A:863-73.

10. Howard CB, McKibbin B, Williams LA, Mackie I. Factors affecting the incidence of hip dislocation in cerebral palsy. J Bone Joint Surg [Br] 1985;67-B:530-2.

11. Lonstein JE, Beck K. Hip dislocation and subluxation in cerebral palsy. J Pediatr Orthop 1986;6:521-6.

12. Sauser DD, Hewes RC, Root L. Hip changes in spastic cerebral palsy. Am J Roentgenol 1986;146:1219-22.

13. Black BE, Hildebrand R, Sponseller PD, Griffin PP. Hip dysplasia in spastic cerebral palsy. Contemp Orthop 1994;29:101-8.

14. Metaxiotis D, Accles W, Siebel A, Doederlein L. Hip deformities in walking patients with cerebral palsy. Gait Posture 2000;11:86-91.

15. Hodgkinson I, Jindrich $\mathbf{M L}$, Duhaut $\mathbf{P}$, et al. Hip pain in 234 non-ambulatory adolescents and young adults with cerebral palsy: a cross-sectional multicentre study. Dev Med Child Neurol 2001;43:806-8.

16. Egger M, Davey Smith G, Schneider M. Systematic reviews of observational studies. In: Egger M, Davey Smith G, Altman DG, eds. Systematic reviews in health care. London, BMJ Books 2001:211-28.

17. Matthews SS, Jones $\mathbf{M}$, Sperling $\mathbf{S}$. Hip derangements seen in cerebral palsied children. Am J Phys Med 1953;32:213-21.

18. Reimers $\mathbf{J}$. The stability of the hip in children: a radiological study of the results of muscle surgery in cerebral palsy. Acta Orthop Scand Supp/ 1980;184:1-100.

19. Goldsmith E, Golding R, Garstand R, MacRae A. A technique to measure windswept deformity: technical evaluation. Physiotherapy 1992;78:235-42.

20. Brunner R, Robb J. Inaccuracy of the migration percentage and center-edge angle in predicting femoral head displacement in cerebral palsy. J Pediatr Orthop B 1996;8:239-41.

21. Portinaro N, Murray D, Bhullar T, Benson M. Errors in measurement of the acetabular index. J Pediatr Orthop 1995;15:780-4.

22. Broughton NS, Brougham DI, Cole WG, Menelaus MB. Reliability of radiological measurements in the assessment of the child's hip. J Bone Joint Surg $[\mathrm{Br}]$ 1989;71-B:6-8.

23. Parrott J, Boyd RN, Dobson F, et al. Hip displacement in spastic cerebral palsy: repeatability of radiologic measurement. J Pediatr Orthop 2002;22:660-7.

24. Faraj S, Atherton WG, Stott NS. Inter- and intra-measurer error in the measurement of Reimer's hip migration percentage. J Bone Joint Surg [Br] 2004;86B:434-7.

25. Pountney T, Mandy A, Gard P. Repeatability and limits of agreement in measurement of hip migration percentage in children with bilateral cerebral palsy. Physiotherapy 2003;89:276-81.

26. Tonnis D. Normal values of the hip joint for the evaluation of $X$-rays in children and adults. Clin Orthop 1976;119:39-47.

27. Pountney T, Green EM. Hip dislocation in cerebral palsy. BMJ 2006;332:772-5. 